\title{
Anatomía arquitectónica en la obra de Eileen Gray. Un análisis comparado para identificar la mano tras el diseño de la E.1027
}

\author{
Architectural Anatomy in the work of Eileen Gray. A \\ Comparative Analysis Identifying the Authorship Behind the \\ Design of the E.1027
}

Autores:

Carlos L. Marcos Alba* carlos.marcos@uc.es María Pura Moreno Moreno** mpuramoreno@gmail.com

*Universidad de Alicante **Universidad Politécnica de Cartagena España a escasa producción arquitectónica de Eileen Gray y su aprendizaje autodidacta, ajeno al ámbito académico, han contribuido a cuestionar su protagonismo en el proyecto de la vivienda E.1027, realizado junto a Jean Badovici, arquitecto y director de la revista L'Architecture Vivante. Esta investigación compara su lenguaje arquitectónico con el de otros de sus proyectos desarrollados en solitario. Se abordan paralelismos e influencias de su obra con aquella modernidad temprana que ella reinterpretaba siempre con una mirada crítica. Dichas comparaciones permiten identificar las cualidades más relevantes de su arquitectura, además de demostrar su protagonismo en el diseño de la E.1027 y relegar a Badovici al papel de consultor técnico, mentor y asesor crítico. La compleja densidad espacial y las relaciones entre lugar, arquitectura y equipamiento se muestran como huellas objetivas para confirmar esta hipótesis y valorar la importancia de su talento como pionera de la modernidad.

Palabras clave: Eileen Gray; E.1027; arquitectura; neoplasticismo.

\section{Abstract:}

Eileen Gray's limited architectural production and her non-academic architectural self-training in architecture have contributed to questioning her role in the authorship of the E.1027, a house designed collaboratively with Jean Badovici, architect and director of the journal L'Architecture Vivante. This article compares the architectural language of the E.1027 house with other projects and works carried out by Eileen Gray alone. Analogies and influences in her work are analysed; an architectural avant-garde at the onset of modernity that she reinterpreted under her attentive critical eye. This methodology has allowed us to identify the most relevant features of her architecture in addition to proof her leading role in the design of the E.1027, thus relegating Badovici's role to that of a technical consultant, a mentor and a critical advisor. The complex spatial density, her particular understanding of the relationships between place, architecture and equipment, confirm our hypothesis supported by objective traces that may avoid the recurring questioning of her authorship accentuating her talent as a pioneer of modernity.

Keywords: Eileen Gray; E.1027; architecture; neoplasticism. 


\section{Introducción}

La vivienda E.1027: Maison en bord de Mer (19261929) diseñada y construida en Cap-Martin (Roquebrune) por Eileen Gray (1878-1976) y su pareja entonces, el arquitecto y crítico rumano Jean Badovici (1893-1956), ha sido objeto, en las últimas décadas, de una atención académica que ha fomentado su interés historiográfico y su reciente restauración. La coreografía entre la arquitectura de la casa y su equipamiento fue analizada monográfica y críticamente en la tesis doctoral de Carmen Espegel Alonso (1997) y en su libro Aires Modernos. E:1027: maison en bord de mer. Eileen Gray y Jean Badovici 1926-1929.

La personalidad esquiva de Gray, junto a su inicio tardío en la arquitectura y su inexistente formación académica, fueron circunstancias que contribuyeron a cuestionar el reconocimiento de su verdadero protagonismo en la autoría de este proyecto; una autoría eclipsada por su colaboración con Jean Badovici pero, sobre todo, por la coyuntura de que algunos de los paramentos de la casa sirvieran de lienzo para ocho murales pictóricos realizados por Le Corbusier en 1937; una actuación considerada por ella - según su biógrafo- como "un acto de vandalismo" (Adam, 2009, p. 135), perpetrado sin su permiso por un compañero arquitecto, un hombre a quien ella admiraba.

En las últimas décadas historiadoras como Caroline Constant (1994), Jasmine Rault (2005) o Beatriz Colomina (2001) han interpretado la factura de aquellos murales como un ataque por parte de Le Corbusier a la intimidad, a la sexualidad e incluso al talento de Gray; algo que, sin embargo, Tim Benton (2017) pone en cuestión al referirse al artículo de Colomina como una interpretación de otro texto anterior de Samir Rafi, que considera no está respaldado por pruebas. Benton (2017) admite la violencia estética causada por las pinturas en aquella arquitectura, pero duda que representaran ningún ataque personal.

Esta polémica extra-arquitectónica ha centrado demasiado el debate en torno a la casa, contribuyendo a diluir su verdadero valor como notable ejemplo de proyecto doméstico. $Y$ ha desviado la crítica arquitectónica; distorsionando la objetividad que le debe ser propia y que Gray reivindicaba con la contundente afirmación: " $L a$ obra bella es más verdadera que el artista" (GrayBadovici, 1929, p. 17). Siguiendo esa premisa, en este texto se obvia deliberadamente la crítica basada en sesgos y preconcepciones centradas en el hecho de que fuese una mujer y su producción quedase ensombrecida por la figura de Le Corbusier o la de Badovici, para centrarnos en demostrar la calidad de lo que realmente proyectó y, lamentablemente, apenas construyó. Dicho triángulo de personajes e intereses fue abordado con anterioridad, prestando especial atención a las más que discutibles intervenciones arquitectónicas alrededor de la E. 1027 por parte de Le Corbusier que otros parecen obviar (Marcos, 2011). En consecuencia, se soslaya la bibliografía de esa historia colateral para atender únicamente al objeto arquitectónico, porque los sujetos, que sí tienen género, pueden alterar la objetividad a la que se debe toda crítica de cualquier obra creativa, tratando de imponer su punto de vista sobre el objeto analizado.

En 1929, la primera vez que se publica la vivienda E.1027 en la revista L'Architecture Vivante se atribuye su autoría, por este orden, a Eileen Gray y Jean Badovici; un orden que evidencia el reconocimiento de Badovici a la incipiente arquitecta al relegarse él mismo a un segundo plano, aun siendo el único arquitecto del tándem y el director de aquella publicación en la que aparecían los planos y fotografías de la casa con una detallada descripción de la misma, junto a un texto dialogado y titulado De l'Eclectisme au Doute. ${ }^{1}$

Durante años, y pese al orden en la atribución de la autoría de aquella primera publicación, las escasas referencias a la casa E.1027 atribuían erróneamente el proyecto a Le Corbusier, o el nombre de Eileen Gray se ocultaba o se escribía mal (Colomina, 2001, p. 50). La vivienda no formó parte de la historiografía de la modernidad - como tampoco lo hizo su segunda casa, Tempe à Pailla - hasta que el crítico J. Rykwert fijó su atención y ponderó la originalidad y calidad de la escasa obra construida de Gray en publicaciones como Domus (1968), Perspecta (1971), y Architectural Review (1972). Probablemente este ominoso olvido no fuera ajeno a la alargada sombra de Le Corbusier y a su influencia en el panorama arquitectónico durante décadas, lo que sin duda contribuyó a eclipsar el protagonismo de Eileen Gray en el diseño de la E.1027, para cuyo esclarecimiento, entre otras cosas, se escribe este artículo.

\section{Metodología de la investigación}

Esta investigación muestra el verdadero papel de cada uno de los coautores, asignando a Gray el papel de proyectista principal. Para ello se emplea el método de análisis comparado sujeto tanto al principio de la navaja de Ockham como al criterio positivista de Auguste Comte, según el cual a partir de los hechos se infieren leyes de fenómenos más complejos por medio de la inducción (Badovici, 1926). Bajo esta metodología, y con una mirada crítica hacia el objeto arquitectónico, se contrasta la vivienda con proyectos anteriores y posteriores realizados por Gray en solitario; así como con algunos de Badovici mucho más influenciados por la impronta de Le Corbusier y sin apenas relación con los principios neoplasticistas abrazados por ella.

${ }^{1}$ Atribuimos a Eileen Gray las respuestas a cuestiones planteadas po Jean Badovici -quien aparenta realizar una entrevista al arquitecto de la obra, aunque se cite a ambos como autores del texto-, a pesar de que algunos críticos cuestionan la doble autoría del texto. 
Anatomía arquitectónica en la obra de Eileen Gray. Un análisis comparado para identificar la mano tras el diseño de la E.1027

La exposición de la casa E.1027 ante el espejo de influencias externas y propias -en las que la autoría de Gray no está en discusión - confirma que este proyecto es un eslabón más dentro de un proceso continuado o, en sus propias palabras "un ensayo, un momento dentro de una investigación más amplia" (Gray-Badovici, 1929, p. 28). Y, sin duda, también un ejercicio de refinamiento en e que Gray estudió cada gesto de la acción de habitar reflejado en la conjunción de arquitectura y equipamiento (Fernández-Cobián, 2013).

Analizando sus proyectos y obras se evidencia la labor fundamental de Gray en la configuración espacial de la casa y en el diseño de todo su equipamiento como obra unitaria. La conclusión relega a Badovici a sus dos verdaderos papeles: en primer lugar, al de asesor en aspectos técnico-constructivos, y en segundo lugar, al de experto, mentor o acompañante que enriqueció el proyecto dialogando con la propia Gray y aportando su mirada crítica. Un enfoque avalado por la extraordinaria selección de arquitectura moderna que publicaba, como director, en L'Architecture Vivante (1923-1933), dirigiéndose a un público exclusivamente profesional. Una revista esta que fue testimonio y testigo coetáneo de la mejor vanguardia arquitectónica de la época, y que mereció ser considerada por Le Corbusier como "el documento más preciso de investigación de la Arquitectura y el Urbanismo contemporáneo", por mostrar de la arquitectura "su anatomía", es decir "aquello que constituye la esencia...los planos, las secciones, los detalles, etc." (Le Corbusier, 1933, p. 33). Sin duda, una publicación que conformó la mejor bibliografía arquitectónica para el aprendizaje autodidacta de Gray en aquel momento de modernidad incipiente.

A continuación, a modo de resultados y discusión, se analizan las influencias de las que Gray aprende y la dialéctica que establece con una modernidad reinterpretada por su particular concepción espacial y su vocabulario formal. La sabia integración de la arquitectura en el lugar, así como sus señas de identidad, tales como la densidad espacial, la coreografía, la escala y la medida, se traslucen en los proyectos analizados para confirmar la hipótesis del protagonismo de Eileen Gray en la autoría de la E.1027.

\section{Auto-aprendizaje, influen- cias y dialéctica moderna: Le Corbusier, J. Badovici y De Stijl}

El espacio de la E.1027, junto a su equipamiento diseñado ad-hoc, ratifica la idea de Gesamtkunstwerk - obra de arte total-; una concepción esencial en los movimientos Arts \& Crafts, Art Noveau o Art Déco que fue reinterpretada por De Stijl como garantía de unidad. El interés de Gray por las artes aplicadas quedó pronto marcado por su idea de concebir una producción útil, contraria a la futilidad del arte per se y confesada en sus palabras "... los dibujos no sirven de nada. Quiero hacer algo útil" (Rykwert, 1972, p. 357). Una preocupación coincidente con la línea de pensamiento de J.L. Cordemoy o F. Milizia, y probablemente aprendida de Badovici, para quien la arquitectura útil "elimina todo aquello que no tiene para la obra utilidad indiscutible y directa" (Badovici, 1926, p. 18).

Esta concepción de armonizar arte y utilidad al servicio de un diseño funcional y sinfónico fue experimentada por Gray en el apartamento de Madame Mathieu-Lévy en la Rue de Lota (1919-1922). Un interiorismo cuya reseña en The Architecturel Press subrayaba la simbiosis entre arquitectura-mobiliario y la conversión de aquella "diseñadora de muebles" en una auténtica "arquitecta constructora de la atmósfera de la casa"; llegando a acuñar para ella el término ensamblier - por su entendimiento conjunto de mobiliario y decoración - y anticipando un futuro arquitectónico caracterizado por un sobrio espíritu zen preocupado por la materialidad artesanal (Adam, 2009, p. 51); unos rasgos probablemente inculcados por su maestro en la técnica del lacado, el japonés Seizo Sugawara, con quien mantuvo su más duradera relación profesional.

Idénticos objetivos quedaron expuestos en su Boudoir de Monte Carlo del Salon des Artistes Décorateurs, en París (1923), un proyecto expositivo jalonado con sus diseños de mobiliario y tapices que fue reseñado en los siguientes términos:

[...] ella concibe el difícil proyecto de crear un conjunto
perfectamente armonioso con la ayuda de una nueva
combinación de líneas... Su objetivo es equipar completamente
un espacio, las cortinas, las texturas, alfombras, telas y todas
las luces con el fin de crear un conjunto que sea un poema (De
Clermont-Tonnerre, 1922, p. 148). Un Boudoir en el que plantea una composición doméstica concebida como un poema construido en el que el espacio debía estar totalmente equipado y cuya armonía traslada a los interiores de sus dos viviendas construidas: la E.1027 y Tempe à pailla (1932-1934) (Figura 1)².

Aquel Boudoir inicial interesó a los arquitectos holandeses Albert Boeken y Sybold van Ravesteyn, quienes elogiaron en la revista Bouwkunding Weekblad la geometría abstracta de sus muebles y el efecto inédito del conjunto. Un reconocimiento este reseñado también en la revista Wendingen $^{3}$, tanto por Jan Wils, que destacó el carácter emotivo de sus piezas, como por un texto de Badovici en el que auguraba el inmediato tránsito de Gray hacia la arquitectura, además de su indiscutible modernidad:

El arte de Eileen Gray se sitúa en el corazón del movimiento moderno. Eileen Gray es moderna [...] por su desprecio hacia las viejas formas plásticas [...] sus realizaciones son testigos de una rara audacia y de una visión singularmente original $[\ldots]$ Eileen Gray será, ciertamente la artista más expresiva de nuestro tiempo (Badovici, 1924, p.12).

Ese interés holandés por su obra, además de en la revista Wendingen - representada por artistas más experimentales y cercanos al expresionismo alemán-, también era mostrado por los del movimiento De Stijl, que Theo van Doesburg consideraba como los auténticos constructores (Zevi, 1960). Estos últimos observaban afinidades entre

2 A las que cabe añadir la rehabilitación de su Villa Lou Perou en St. Tropez (1954-61) y algunas intervenciones de interiorismo y reacondicionamiento, como su apartamento de la calle Bonaparte 21 (1930) y el apartamento de Badovici (1929-31), en la calle Chateaubriand 7, ambos en París.

${ }^{3}$ La revista Wendingen (1918-1926) era el instrumento de divulgación de la Escuela de Ámsterdam y sus portadas constituyeron una excepcional contribución a la historia de la tipografía y el grafismo moderno. 

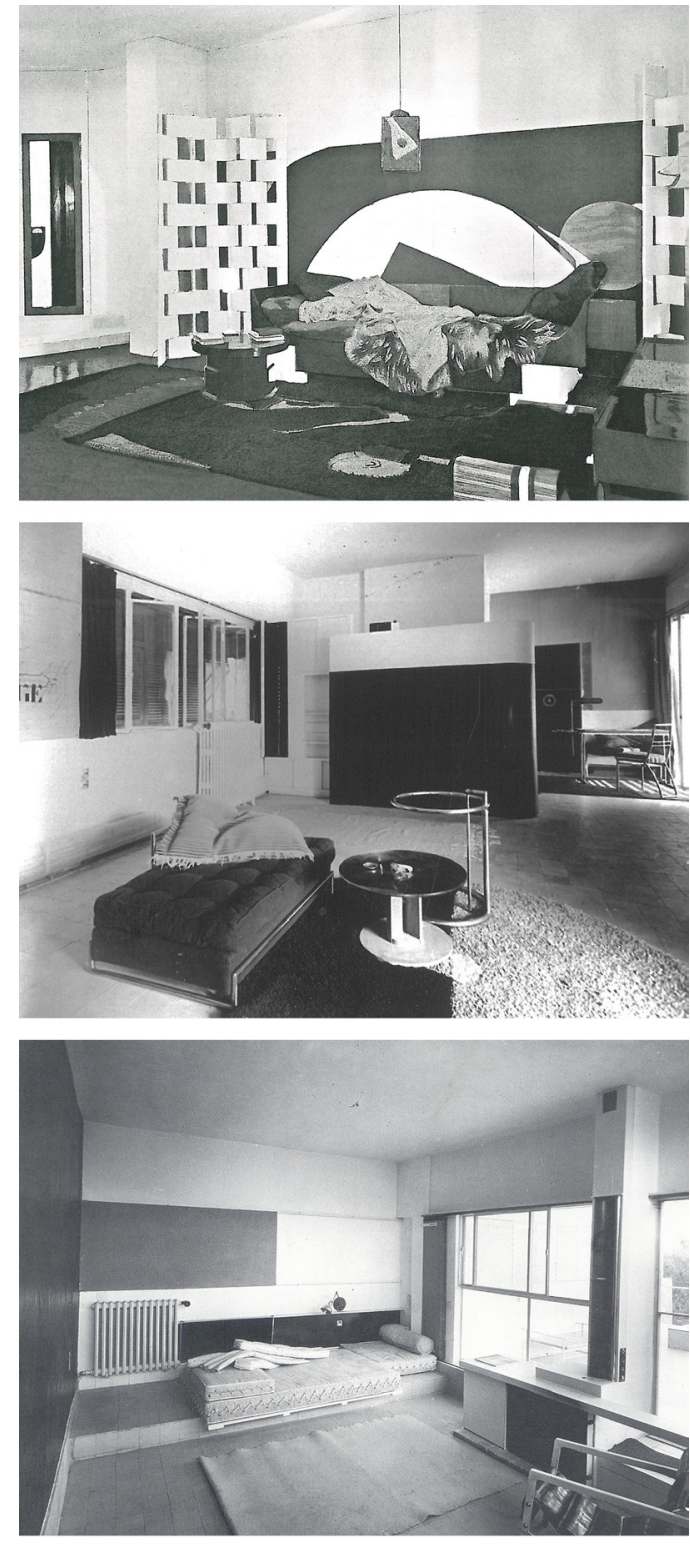

Figura 1: 1A. Boudoir de Monte Carlo en el Salon des Artistes Décorateurs de París (1923). 1B. Estancia principal de E.1027. Maison en Bord de Mer (1926-1929). 1C. Estancia principal de Tempe à pailla (1932-1934) Fuente: A: Constant, 2000, 50. B: Espegel, 2011, 67. C: Adam, 2009, 236

las combinaciones de las líneas compositivas de sus muebles y alfombras - exhibidos en su Galería Jean Desert (Constant, 2000, p. 43) - y los enunciados neoplasticistas referidos a la integración en espacio y mobiliario de los conceptos de forma, economía, función, luz y tiempo: unas características anticipadoras del entendimiento de la unidad global de su futura obra arquitectónica.

Aquella admiración desde el ámbito holandés quedó también demostrada en la carta dirigida por Jacobus Johannes Pieter Oud a Gray, en la que trataba de averiguar si ella abanderaba algún movimiento emergente desconocido.

¿Podría enviarme alguna publicación de sus obras? [... ¿Pertenece a algún movimiento nuevo en su país? (Constant, 2000, p. 54).
En ese contexto de intereses cruzados con el neoplasticismo, Gray se inicia en su primer proyecto arquitectónico: una reinterpretación de la Villa Moissi de Adolf Loos $^{4}$, en lo que podría parecer un ejercicio de escuela planteado por un profesor a su alumna - ¿j. Badovici a E. Gray?-. Su elaboración comienza con el calcado, casi exacto, de tres de sus alzados y una sección, que son modificados en dos versiones posteriores introduciendo un repertorio arquitectónico influenciado por la Maison Citrohan o el Atelier Ozenfant de Le Corbusier, ambos de 1922: ventanas horizontales, acristalamiento de doble altura en el salón, o situación elevada del piano nobile (Moreno, 2012, p. 196); un ejercicio en cuya última versión aparecen dos decisiones dignas de mención en alguien que balbuceaba sus primeras líneas arquitectónicas. La primera es la posición de la escalera exenta que daba acceso a la planta noble a través de una amplia terraza de ingreso; solución que, sorprendentemente, anticipaba la de la Villa Stein-de-Monzie en Garches (1926) de Le Corbusier. Y la segunda, la descomposición de la volumetría cúbica original con un cuerpo volado de menor altura en la planta superior, que delataba ya su vocación neoplástica de descomposición formal, reflejada claramente en una axonometría de arquitecta principiante (Figura 2).

El hecho de que la influencia ejercida por Badovici fuera más relevante en el ámbito teórico que en el práctico corrobora la hipótesis de la escasa relevancia del arquitecto en la autoría del diseño de la E.1027, sobre todo si se analiza su limitada producción en solitario, apenas reducida a la restauración de cinco casas abandonadas en la localidad Vézelay, unas casas que el arquitecto compró en 1926 con ayuda financiera de Gray para crear una colonia de artistas y en cuyos proyectos ambos comenzaron a colaborar aportando ella su experiencia como diseñadora e interiorista (Constant, 2000, p. 79). ${ }^{5}$ Le Corbusier, visitante asiduo de aquellas viviendas, las publicó en La Ville Radieuse (1933) - atribuyéndolas únicamente a Badovici- y reconociéndole la cualidad de su control dimensional.

[...] cada cosa es mínima, pero a su vez grande. Es un lugar de bienestar, de calma, de diversidad de medida y proporción, de dimensiones completamente humanas (Le Corbusier, 1964, p.54).

Unos rasgos característicos de la obra de Gray, estos, que fueron resignificados en la publicación posterior de la casa en 1930, en el primer número de la nueva revista L'Architecture d'Aujourd'hui, bajo el título La Maison mínimum: Pour le mínimum de place. Le maximun de confort. Cellules fixes \& Cellules Transformables (Gray y Badovici, 1930).

Los alzados realizados por Badovici para su casa en Vézelay (Figura 3A), de fuerte impronta corbusierana, incluían la literalidad de los trazados reguladores y una concepción cúbica de la vivienda con una distribución interior poco novedosa, en contraste con los aires levemente

${ }^{4}$ El proyecto-no construido- de la "Villa Moissi" del arquitecto Adolf Loos había sido expuesto en el Salón de Otoño de París de 1923, y sus planos, junto a las fotografías de su maqueta, ilustraron el artículo "L’Architecture et le Style Moderne", publicado por Badovici en el primer número de L'Architecture Vivante en 1923.

${ }^{5}$ Según investigaciones recientes de Tim Benton el papel de Gray en estas rehabilitaciones debió ser más testimonial que efectivo, algo en lo que parece estar de acuerdo C. Constant, y en lo que sigue actualmente trabajando T. Benton. 
Anatomía arquitectónica en la obra de Eileen Gray. Un análisis comparado para identificar la mano tras el T
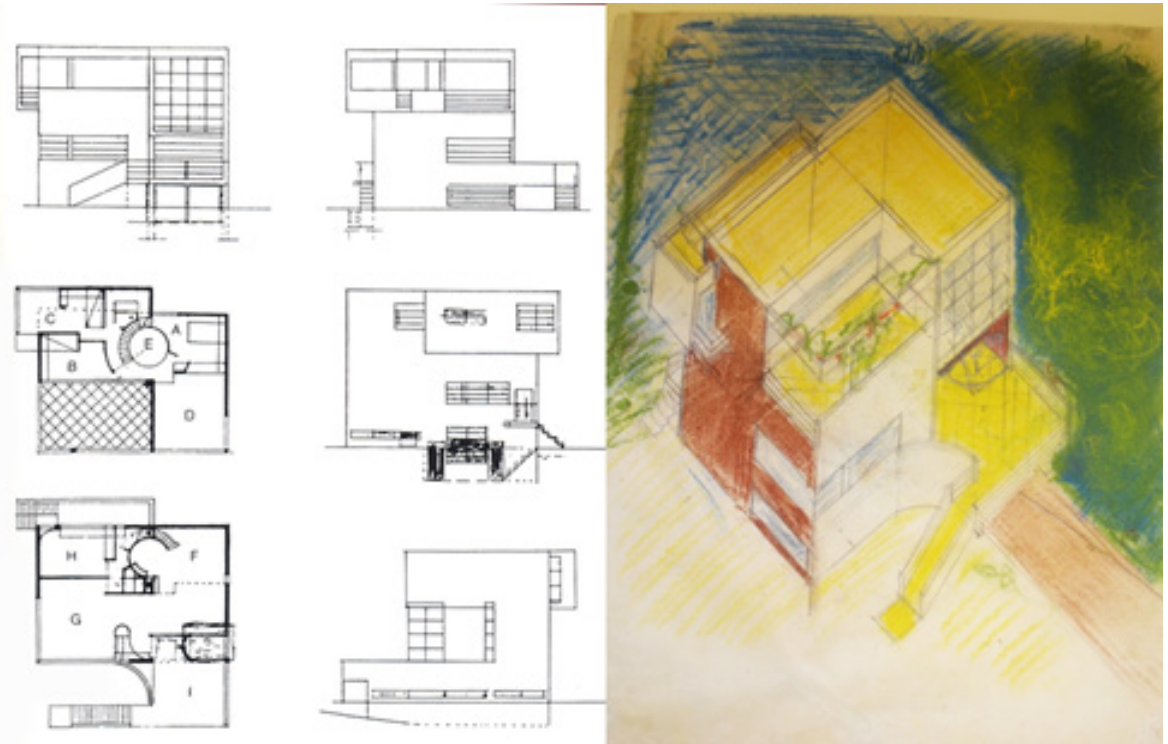

Figura 2: 2A Plantas y Alzados. 2B. Axonométrica de Tercera versión del Provecto "Vivienda de Tres Plantas" basado en "Villa Moissi" de Adolf Loos (1923)

Fuente: A: V\&A Museum AAD/1980/9/172/4. B. V\&A Museum AAD/1980/9/171/1
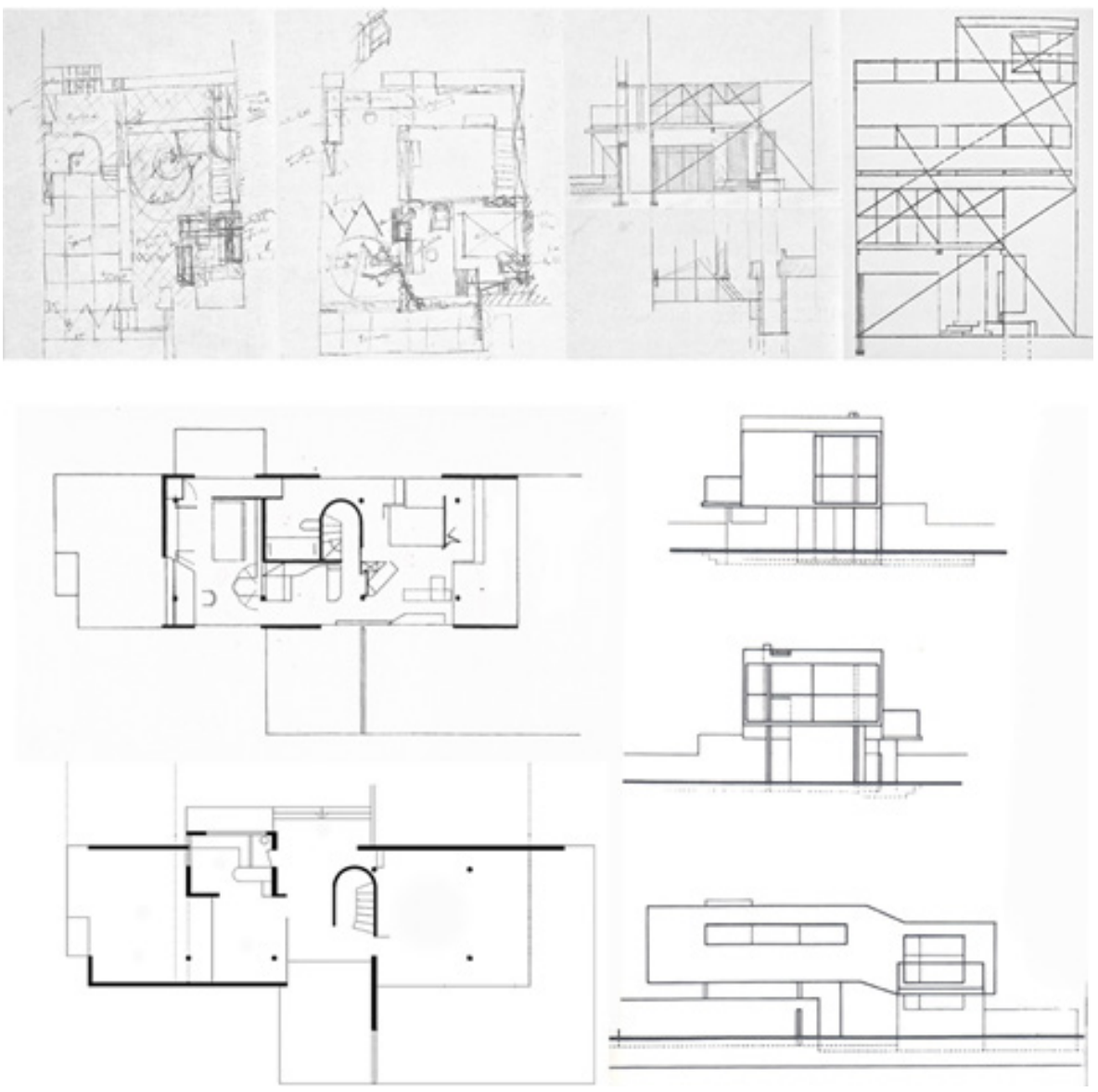

Figura 3: 3A. Casa de Jean Badovici en Vézelay, 1927-1931. 3B. Plantas y 3C Alzados de "Maison pour un ingénieur dans le midi" (1926)

Fuente: A: V\&A Museum AAD/1980/9/239/1-8. B: National Museum of Ireland NMIEG 2000.250. C: V\&A Museum AAD/1980/9/211/4-6 
neoplasticistas de Gray en su reinterpretación de Villa Moissi. Esa estética holandesa estaba presente en el contexto profesional de la pareja a través de sus contactos con arquitectos holandeses y de la publicación en L'Architecture Vivante de textos de P. Mondrian, Theo van Doesburg, y obras como la casa Schröeder de Schröder y Rietveld, que ambos visitaron en 1925 (Constant, 2000, p. 77).

Sin dichas influencias, es impensable comprender la extraordinaria originalidad del segundo proyecto de Gray en solitario, realizado en el año 1926 - un año clave en su trayectoria - la Maison pour un Ingénieur dans le mid de la France (Figura 3B y 3 C); un proyecto que puede ser considerado como su verdadera opus prima y el auténtico precedente de la E.1027 (1926-1929) y de Tempe à pailla (1932-1934) - ; un proyecto imaginario en el que, por primera vez, experimenta ex novo sin las preexistencias propias de una reforma interior o de un proyecto heredado que condicionara su diseño.

Su planta baja prolongaba los muros organizando en niveles diferentes estancias de una fluidez espacial similar a la de la Maison Particulière de Theo van Doesburg y Cornelis van Eesteren, o de la Casa de Ladrillo de Mies van der Rohe, ambas de 1923. El volumen compacto de su planta primera descansaba sobre unos pilotes retranqueados de la línea de fachada, lo que permitía unas ventanas horizontales, además de una cubierta plana, apelando a los cinco puntos de la arquitectura moderna de Le Corbusier. Esa combinación se mezclaba con innovaciones más maduras, como la utilización híbrida de pilares de sección circular - pilotis - y muros que ejercían de elementos portantes. Todo ello configurando una dialéctica que anticipaba el lenguaje de la casa Tugendhat (1929), de Mies van der Rohe, con la que compartía sorprendentemente la posición, la forma y el papel "morfoplástico" del volumen semicircular de la escalera, pero cuya fluidez espacial superaba incluso a la del maestro

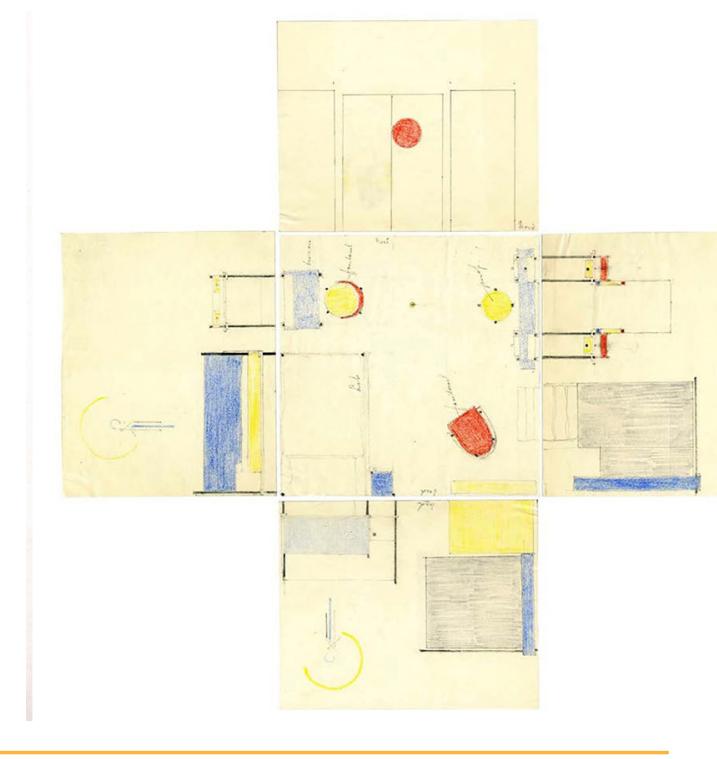

alemán (Rayon, 1985).Badovici, con su acreditado olfato crítico, debió quedarse impresionado por aquel proyecto en 1926, y probablemente por esa razón, a pesar de la escasa experiencia como interiorista e incipiente arquitecta, la invitó a colaborar en los proyectos de Vézelay y en el proyecto común de la casa E.1027 en la Costa Azul; un hecho que resulta significativo si se tiene en cuenta su formación como arquitecto, su posición como director de L'Architecture Vivante y su contacto personal con los arquitectos más sobresalientes de la modernidad; factores que también demuestran su confianza en el trabajo y en la sensibilidad de una Gray, cuyo talento ya había logrado cautivarle por las "cualidades de su visión y de su expresión" (Badovici, 1924, p. 12).

\section{Concepción espacial y vocabulario formal}

El sistema de representación gráfica empleado en los planos publicados en L'Architecture Vivante, en el número de otoño-invierno de 1929 (p. 41), para el dormitorio y baño principal de la E.1027 - una planta rodeada de alzados interiores abatidos en los cuatro flancos - coincide con el del ejercicio de reinterpretación de Villa Moissi y con los de cada una de las estancias de Tempe à pailla. Se trataba del denominado american method con el que T. van Doesburg publicó en L'Architecture Vivante su Flower Room, en 1925, o con el que Sybold van Ravestey representó el espacio y el mobiliario de la habitación diseñada para la Villa Noailles (Figura 4A) - para la que E. Gray había aportado también alguna de sus alfombras-; una narrativa neoplástica utilizada por ella en el diseño de sus muebles - mesa D'Stijl o silla Non Conformist-y depurada en los planos de la E.1027 (Figura 4B) y de Tempe à pailla; un grafismo con el que representaba la adjetivación del espacio a través de un equipamiento del que se detallaba cualquier movimiento de rotación, abatimiento o despliegue.

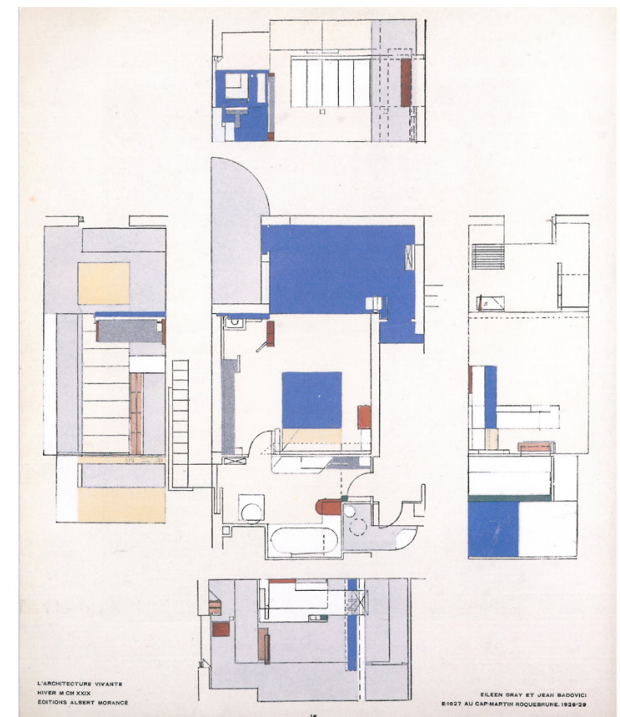


Anatomía arquitectónica en la obra de Eileen Gray. Un análisis comparado para identificar la mano tras el diseño de la E.1027

El cromatismo del plano de la habitación principal de la E.1027, publicado en L'Architecture Vivante, se aproximaba al de las contra-construcciones de T. van Doesburg allí limitado a estrictos colores primarios - exhibidas en la exposición colectiva neoplasticista de la Galerie Leonce Rosenberg en 1923; una exposición que causó gran impacto en el ambiente arquitectónico parisino ${ }^{6}$.

Aquellos postulados neoplásticos influían en la composición de sus tapices, en sus muebles e introducían una espacialidad que diluía la frontera entre arquitectura y equipamiento, configurando un discurso polifónico con matices contrapuntísticos; una concepción presente en E.1027 y en Tempe à pailla, donde ella abogaba por la disolución de los límites del espacio enunciada en e punto $\mathrm{n}$-12 de la arquitectura neoplasticista, y por una arquitectura "anti-cúbica" de "células espaciales" que articularan los diferentes usos (Van Doesburg, 1925, pp.
19-20). Buena parte de aquellos enunciados emergían tanto en estas dos obras como en su discurso teórico. La "nueva arquitectura es anti-decorativa", afirmaba el punto no16 neoplasticista, si bien ella, haciendo gala de una madurez interpretativa, planteaba algo más radical, como que "La arquitectura debería ser su propia decoración" (Gray-Badovici, 1929, p. 19), introduciendo con ello una nueva concepción del habitar más vinculada a la noción de morada.

Un habitar protagonizado en la E.1027 por una sofisticada sala transformable y abierta a la gran cristalera de la terraza, (Figura 5A), que fue reinterpretada en Tempe à pailla (Figura 5B) con una compartimentación más elaborada, donde seguía proponiendo espacios anti-cúbicos prolongados por muros, pasarelas y vistas al exterior, incorporando también lo aprendido en su Maison pour un ingénieur.

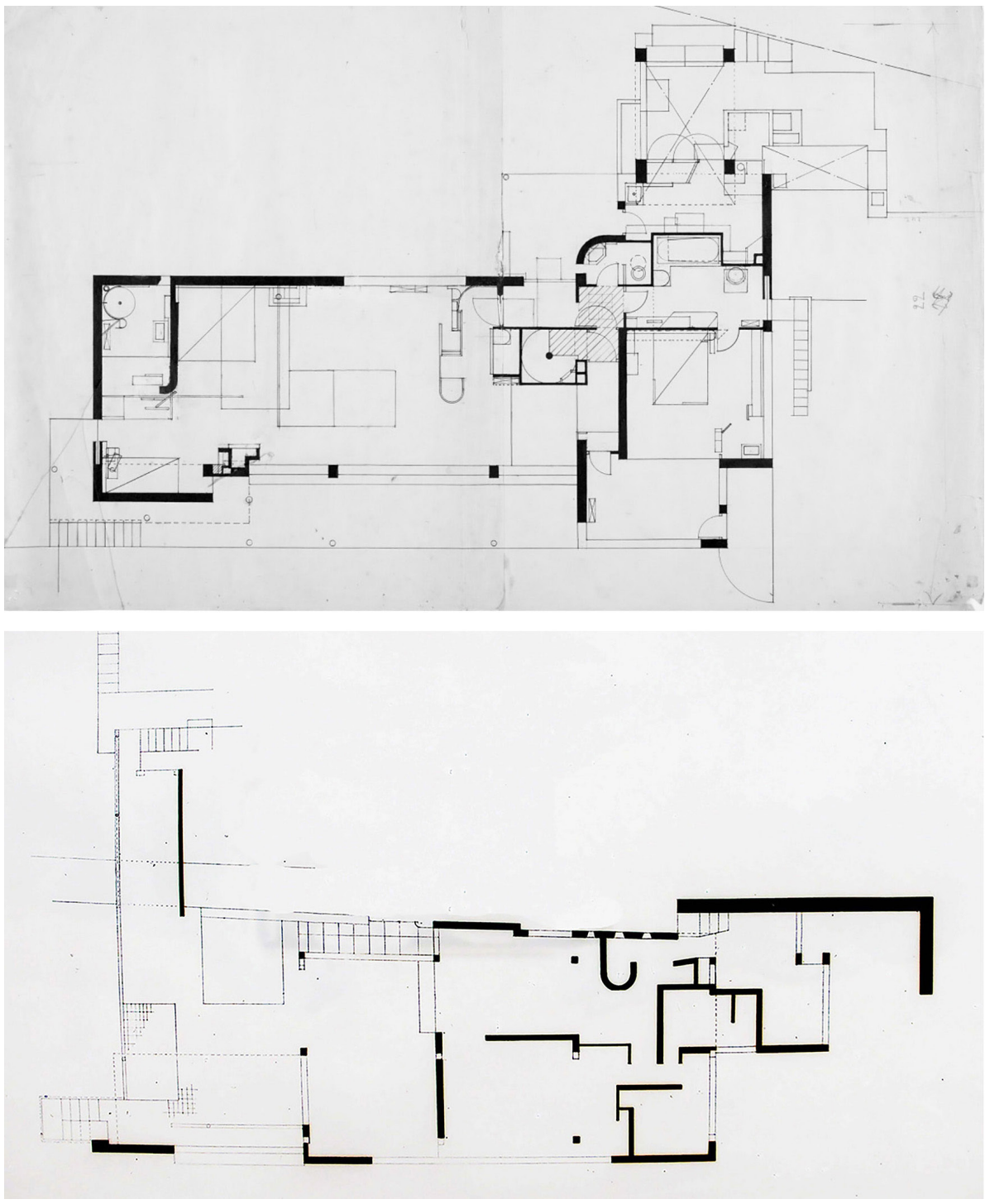

Figura 5: 5A. Planta de E.1027. Maison en bord de mer (1926-1929). 5B. Planta de Tempe à pailla (1932-1934) Fuente: A: National Museum of Ireland NMIEG 2000.250. B: V\&A Museum AAD9/82-1980

${ }^{6}$ Theo van Doesburg afirmaba que Mallet-Stevens y Le Corbusier: "no solo habían visitado la exposición de De Stijl, sino que habían tomado apuntes de ella" (Van Doesburg, 1927, p. 56) 
Tempe à pailla, al ser proyectada para sí misma - ya sin Badovici- entrañaba un diseño más intimista y un equipamiento más austero. Ella, como habitante principal, sin más compañía que la de su asistente personal, necesitaba responder al problema de la intimidad de modo diferente al abordado en la E.1027, cuya estancia principal de $14 \times 6,30 \mathrm{~m}$. fue concebida como una sala polivalente (Gray y Badovici, 1929, p. 30)

Los ecos de aquel espíritu sobrio e inequívocamente moderno de su Boudoir de Montecarlo reaparecen en estas dos viviendas conformando dos poemas de un habitar contemporáneo liberado ya de reminiscencias Déco. En esa nueva concepción, en la que el interior adquiere todo el protagonismo, convergen tanto la influencia de la estética abstracta de la arquitectura neoplasticista como su propia experiencia previa como interiorista. Ambas viviendas suponían una crítica a la preocupación por la estética exterior que caracterizaba buena parte de la vanguardia arquitectónica, aparentemente más interesada por encontrar 'el lirismo del juego de volúmenes y masas del exterior', obviando el bienestar del habitante; algo que ella cuestionaba, aludiendo a que para cierta vanguardia pareciera que "una casa debiera ser concebida para el placer de los ojos más que para el bienestar de sus habitantes"(Gray y Badovici, 1929, p. 28), vinculando utilidad y confort con el diseño esmerado en sus detalles.

Esa concepción se reflejaba también en un proyecto posterior - menos conocido- denominado Four-Story Villa, cuya planta de dormitorios respondía a una mayor complejidad programática. Su repertorio formal y conceptual coincidía con lo experimentado en la E.1027 y en Tempe à pailla, y parcialmente en la Maison pour un ingénieur, lo que corrobora su autoría común. Su programa, desarrollado en cuatro plantas, incluía salones a doble altura, visiones diagonales, divisiones interiores en sincronía con el mobiliario, y una organización reflejada exteriormente a través de volumetrías o logias prolongadas a la parcela; una complejidad con la que continuaba cincelando un lenguaje similar al de proyectos previos, pero aportando una mayor descomposición de planos de inspiración neoplasticista.

Todas estas analogías sintácticas y paralelismos en la concepción espacial de estos proyectos recorridos en la temporalidad de apenas una década demuestran el proceso de prueba y error llevado a cabo por Gray, y permiten contemplar la E.1027 como ese estadio intermedio de una investigación en curso. Sus relaciones cruzadas y el modo en el que, progresivamente, el vocabulario formal se afianza, confirman que lo aprendido es constantemente reinterpretado y matizado en función de las necesidades del programa, del lugar y de las referencias arquitectónicas contextuales (Figura 6).

\section{La integración de arquitectura en el lugar}

Un aspecto que hermana la manera de proceder en la E.1027 con Tempe à pailla y que continúa avalando la hipótesis de su protagonismo en la autoría de la primera, tiene que ver con la excepcional integración de la arquitectura en el emplazamiento; una sabia apropiación del lugar contraria a aquella modernidad ajena el entorno y, sin embargo, mucho más cercana a la arquitectura de F. L. Wright, para quien el entendimiento del lugar era una condición indispensable en la materialización de su arquitectura. Quizá no por casualidad fue el arquitecto americano más influyente en De Stijl, cuyos representantes conocían su obra a través de la edición Wasmuth, publicada en 1910 en Berlín (Frampton, 1987, p. 153).

En ambas casas, Gray interpreta el lugar en toda su plenitud, incorporando las vistas y las preexistencias como los bancales en Cap Martin, a orillas del Mediterráneo, o las cisternas preexistentes en Castellar; siempre con la mejor orientación solar y optimización de la ventilación en función de brisas marinas y vientos dominantes, fruto
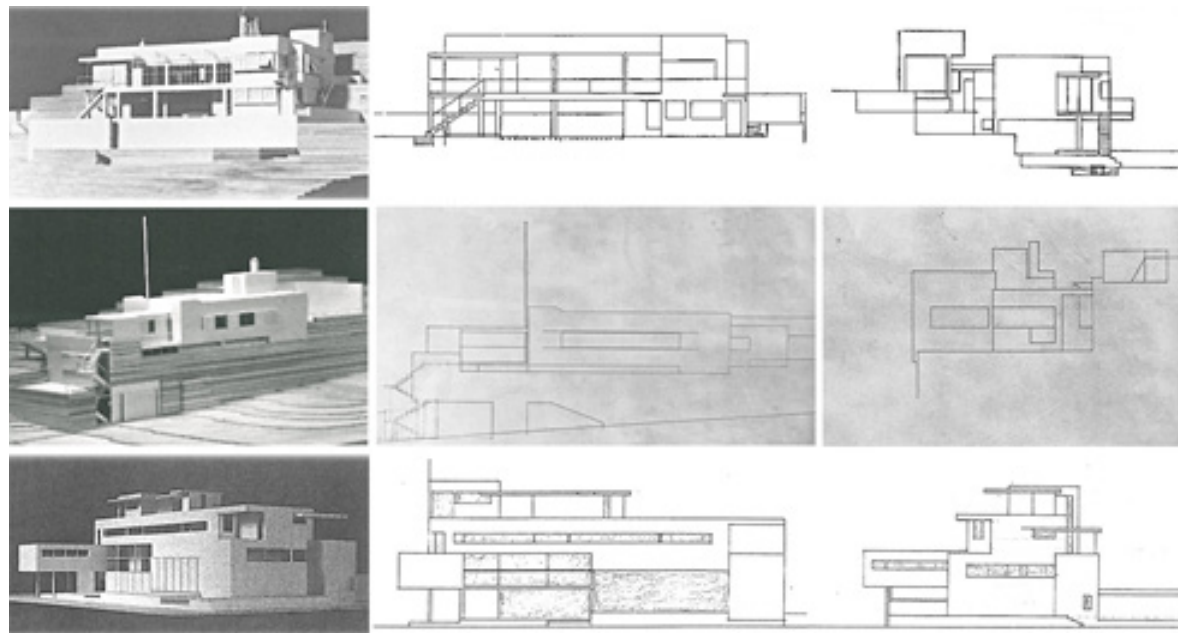

Figura 6: Maquetas y alzados. 5.A E.1027. Maison en Bord de Mer (1926-1929). 5. B Tempe à pailla (1932-1934). 5C. Vivienda de cuatro plantas

Fuente: A: Foto de Maqueta "E.1027" en libro Constant, 2000, p. 213. Alzados en L’Architecture Vivante, Otoño-Invierno 1929, 22. B: Foto de Maqueta "Tempe à pailla" en Constant, 2000, 215. Alzados en V\&A Museum, AAD9/81-1980. C: Foto de Maqueta reconstruida por Leslie Hauser, Steve Belflower y Todd MacDowell en 1992-1993, fotografiada por Richard Steinmetz, recogido en Constant \& Wang, 1995, 177. Alzados V\&A Museum AAD/1980/9/175/1-3 
Anatomía arquitectónica en la obra de Eileen Gray. Un análisis comparado para identificar la mano tras el diseño de la E.1027

de su interés por la adecuación climatológica y de cultura local -la cocina exterior de E.1027 para su disfrute en el buen tiempo -(Figura 7).

Dicha preocupación de adecuar su arquitectura a las condiciones externas queda contrastada tanto en el vocabulario exterior de ambas viviendas (Figura 8) como en dos diagramas efectuados con similar grafismo, en los que expone la relación entre habitante, arquitectura y entorno, registrando lo móvil - la trayectoria solar y las circulaciones - frente a lo estático - los límites físicos de la arquitectura-(Figura 9). En el diagrama de la E:1027, la trayectoria del Sol la describe con la rotación de la tipografía de la palabra "Soleil" en los flancos soleados, mientras en el de Tempe à pailla el sol se dibujaba en su cenit, indicando la zona soleada de la casa. Ambos esquemas expresaban un contexto arquitectónico que aspiraba a ser científico y buscaba la optimización del espacio impulsada por el II Congreso de los CIAM en Frankfurt (1929), donde el concepto de vivienda mínima evolucionó hacía el de "mínimo de vivienda" (Wohnunng minimum), referido al aire, luz y espacio. Ese cientifismo era ya apuntado por Badovici, para quien la arquitectura moderna "quiere aproximarse a la ciencia pura, cuyas leyes imita y quiere traducir con rigor" (Badovici, 1926, p. 18)

El interés de Gray por el soleamiento en relación con la organización espacial denotaba su dimensión fenomenológica como definidora del espacio. No en vano la ligera rotación de la fachada principal en la E.1027 respecto de los bancales pre-existentes se correspondía con bastante precisión con el eje definido por los azimuts del amanecer en el solsticio de invierno, y del anochecer en el solsticio de verano (Ryan, 2010, p.341); un detalle no casual si recordamos su entusiasmo por los misterios de las ruinas aztecas de Teotihuacán o por las de Stonehenge, cuyas láminas eran de las pocas licencias decorativas que se permitió en las paredes de sus viviendas (Constant, 2000, p. 148)

El sol, en ambos casos, atravesaba las cubiertas en lugares estratégicos. En la E.1027, gracias a una escalera de caracol con envolvente transparente en el casetón de cubierta, y en Tempe à pailla a través de un lucernario dotado de un sofisticado deflector que controlaba la luz en el interior de la suite principal, ejerciendo de auténtico reloj sol.

Esa adaptación técnica y constructiva del diseño arquitectónico al lugar y a la climatología desembocaba en unas excelentes condiciones de confort, sin necesidad de recurrir a sistemas mecánicos de climatización. Así la E.1027, a pesar de estar situada estratégicamente en la Riviera francesa, goza de una conocida benignidad climática en la que colabora el diseño de soluciones pasivas - protecciones frente al soleamiento, ventilación cruzada, ganancia térmica, o apertura estratégica de huecos y orientación - logrando que su interior permanezca en perfecto confort higrotérmico entre abril y octubre (Galiano et al., 2021)

Asimismo, la complejidad material de acabados y colores evidenciaba el efecto que la luz producía en ese espacio denso conformado por equipamientos en los que abundaban las superficies mateadas, cromadas, vítreas o coloreadas, creando una atmósfera sofisticada y precisa; algo evidente si se observan los interiores de la casa
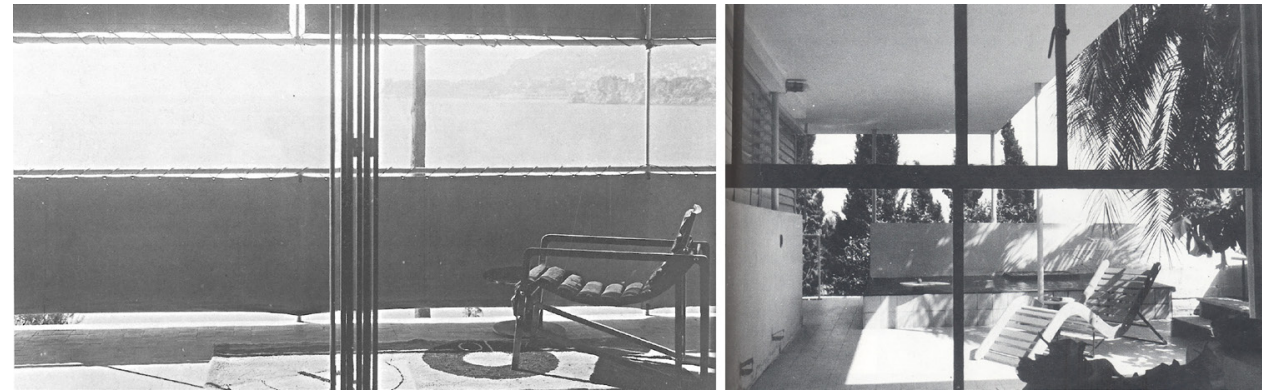

Figura 7: 7A. Terraza de E.1027. Maison en Bord de Mer (1926-1929). 7B. Terraza de Tempe à pailla (1932-1934) Fuente: A: L'Architecture Vivante, Otoño-Invierno 1929,.37. B: Adam, 2009, 227
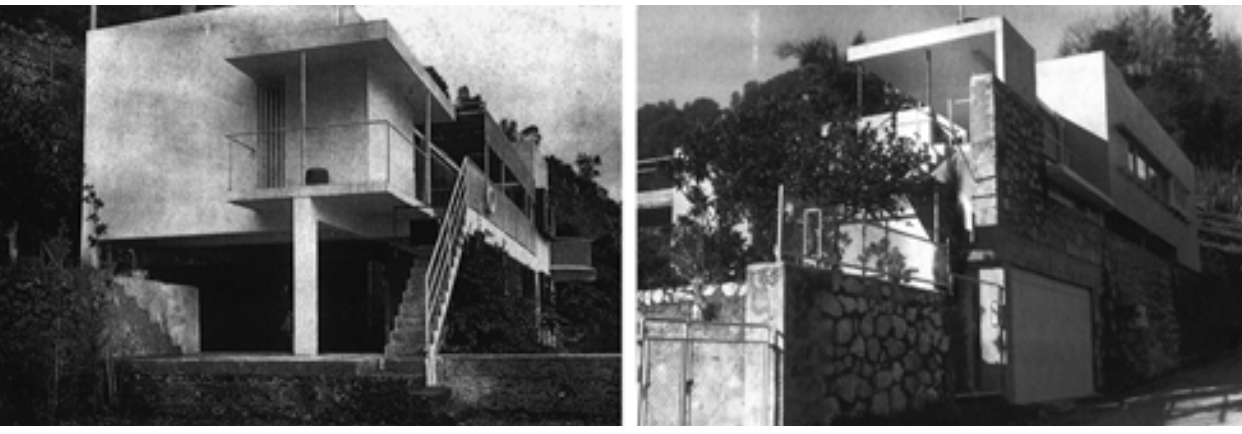

Figura 8: 8A. Exteriores de E.1027. Maison en Bord de Mer (1926-1929). 8B. Exterior de Tempe à pailla (1932-1934) Fuente: A: L’Architecture Vivante, Otoño-Invierno 1929, 28. B: Adam, 2009, 221 

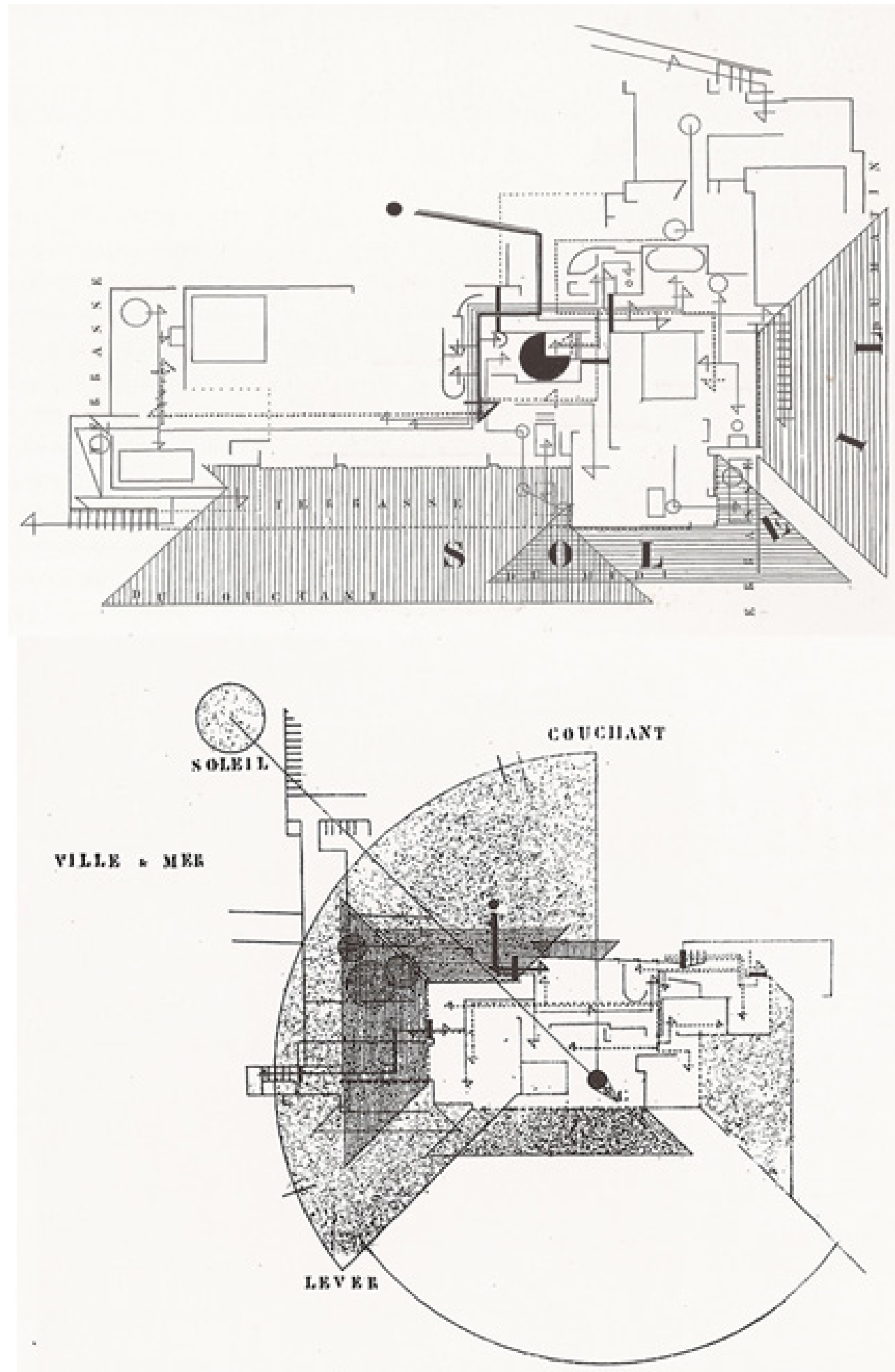

Figura 9: 9A. Plano de soleamiento y circulación E.1027. Maison en Bord de Mer (1926-1929) 9.B Plano soleamiento y circulación. Tempe à pailla (1932-1934)

Fuente: A: V\&A Museum AAD/1980/ 9/188/29. B: National Museum of Ireland NMIEG 2003.Cat 128 
Anatomía arquitectónica en la obra de Eileen Gray. Un análisis comparado para identificar la mano tras el diseño de la E.1027

tras la cuidadosa restauración capitaneada por la asociación Cap Martin Modern, entre 2014-20207. Una rehabilitación que delata la personal interpretación de Gray respecto al precepto $\mathrm{n}$ 16 de De Stijl, según el cual "e color no tiene un valor ornamental, sino que es un medio elemental de la expresión arquitectónica" (Van Doesburg, 1925, pp. 19-20). Gray hace un uso intencional del color creando un efecto focal en puntos concretos del espacio, estableciendo así un diálogo entre los tonos neutros del conjunto y los acentos de color, textura o factura de los materiales.

\section{Densidad espacial, coreografía, escala y medida}

La optimización del espacio en aquellas coreografías arquitectónicas ensayadas deviene inmediatamente en otra experimentación que abunda en la hipótesis inicia de demostrar su protagonismo en la autoría de la E.1027. Se trata del apartamento para Badovici en la Rue de Cha teaubriand (1929-1931) de París, en el que, como en su propio apartamento de la Rue Bonaparte de París, desarrolla "esa atmósfera mecánica que tímidamente había anticipado en la E.1027" (Marín de Terán, 1976, p. 13). Una atmósfera análoga a la "poesía técnica" sugerida por Kenneth Frampton (1988, p. 26-43) en la Maison de Verre (1928-1932) de Pierre Chareau, en la que lleva a cabo e "más difícil todavía" al habilitar una planta mínima a través de un elemento equipado en la entrada que alberga el baño y en el que introduce un falso techo de almacenaje doméstico (Morales, 2005, p. 35). Procuraba as otros lugares de almacenaje que continuaría desarrollando en Tempe à pailla o en las estanterías de la escalera interior en la E.1027, muchos de ellos suplementados por una serie de mecanismos ingeniosos para su fácil acceso que diseñaba con esmero para maximizar la habitabilidad del interior (Moreno, 2017).
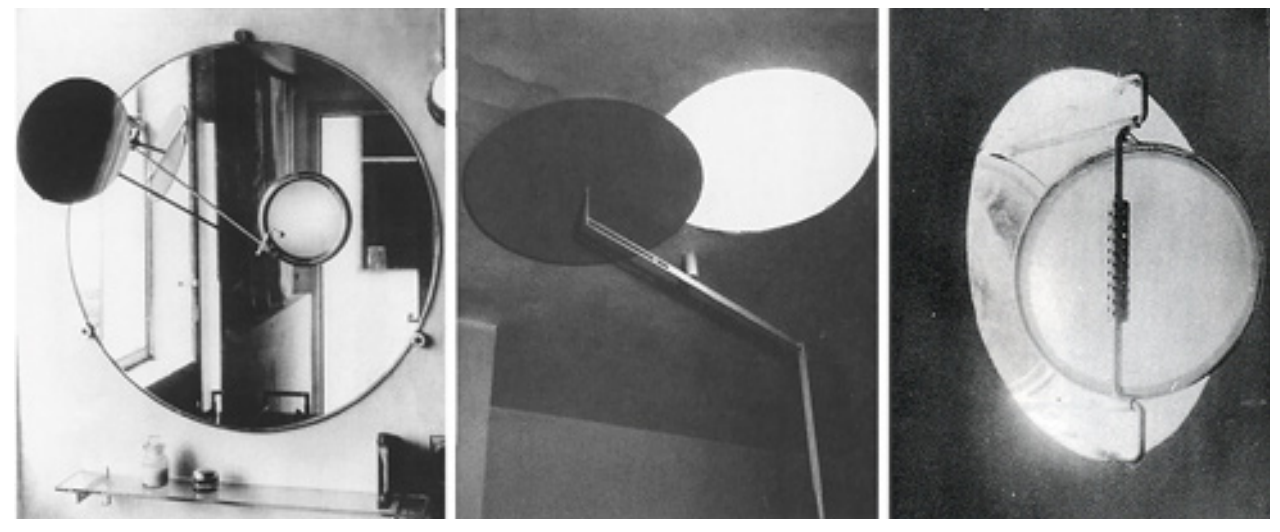

Figura 10: 10A. Espejo de baño de E.1027. Maison en Bord de Mer (1926-1929). 10B. Lucernario de dormitorio principal de Tempe à pailla (1932-1934). 10C. Ventana de alzado oeste de Tempe à pailla

Fuente: A: L’Architecture Vivante, Otoño-Invierno 1929, 45. B: Adam, 2009, 125. .C: Constant, 2000,151

${ }^{7}$ Dicha restauración fue abordada previamente a su ejecución en textos como el redactado por Renaud Barrés en el capítulo titulado “E:1027: vers une restauration active d'un manifeste de l'architecture moderne" del libro Essai d'une théorie de restauration active du patrimoine moderne et contemporain. Editions de l'Espérou, 2000
El diseño de esos objetos de equipamiento contribuía a la cualificación espacial y a la interacción entre el habitante y la arquitectura con un despliegue sensual en todos sus proyectos. El espejo satélite (Figura 10A) diseñado para el baño de la E.1027, permitía rasurarse el pelo de la nuca con un hábil juego de reflejos; el lucernario de Tempe à pailla (Figura 10B) dosificaba la luz por medio de un mecanismo rotatorio; lo mismo sucedía con su ventana circular de estética náutica, dotada de un ingenioso sistema de apertura (Figura 10C). Estas analogías mecanicistas referidas al uso del camping style, la exhibición de instalaciones, el diseño de diferentes diafragmas para las carpinterías o la hiperfuncionalidad de espacios gracias a su mobiliario (Espegel, 2010, p. 154) son, sin duda, características exclusivas del ingenio de Gray que cuestionaban la concepción de machine d'habiter propugnada por Le Corbusier; una concepción que ella criticaba abiertamente con afirmaciones como que la "mecanización intoxica a la vanguardia" (Gray-Badovici, 1929, p. 20), o más explícitamente, "la casa no es una máquina en la que vivir" (Adam, 1987, p. 319), en lo que parece una alusión directa al maestro suizo.

Aquella rica adjetivación del interior obedece a una refinada y compleja densidad que vincula arquitectura y mobiliario en un ensemble polifónico puesto al servicio de habitante; una referencia musical ya sugerida por Badovici cuando la interpela diciendo "Deseas que tu arquitectura sea una sinfonía en la que todas las manifestaciones internas vitales sean expresadas"; a lo que ella respondía con un explícito "Exactamente" (Gray-Badovici, 1929, p. 19)

La noción de habitar y la compresión de la casa como morada trasciende cualquier limitación puramente visual, aproximándose a una fenomenología multisensorial (Figura 11). 

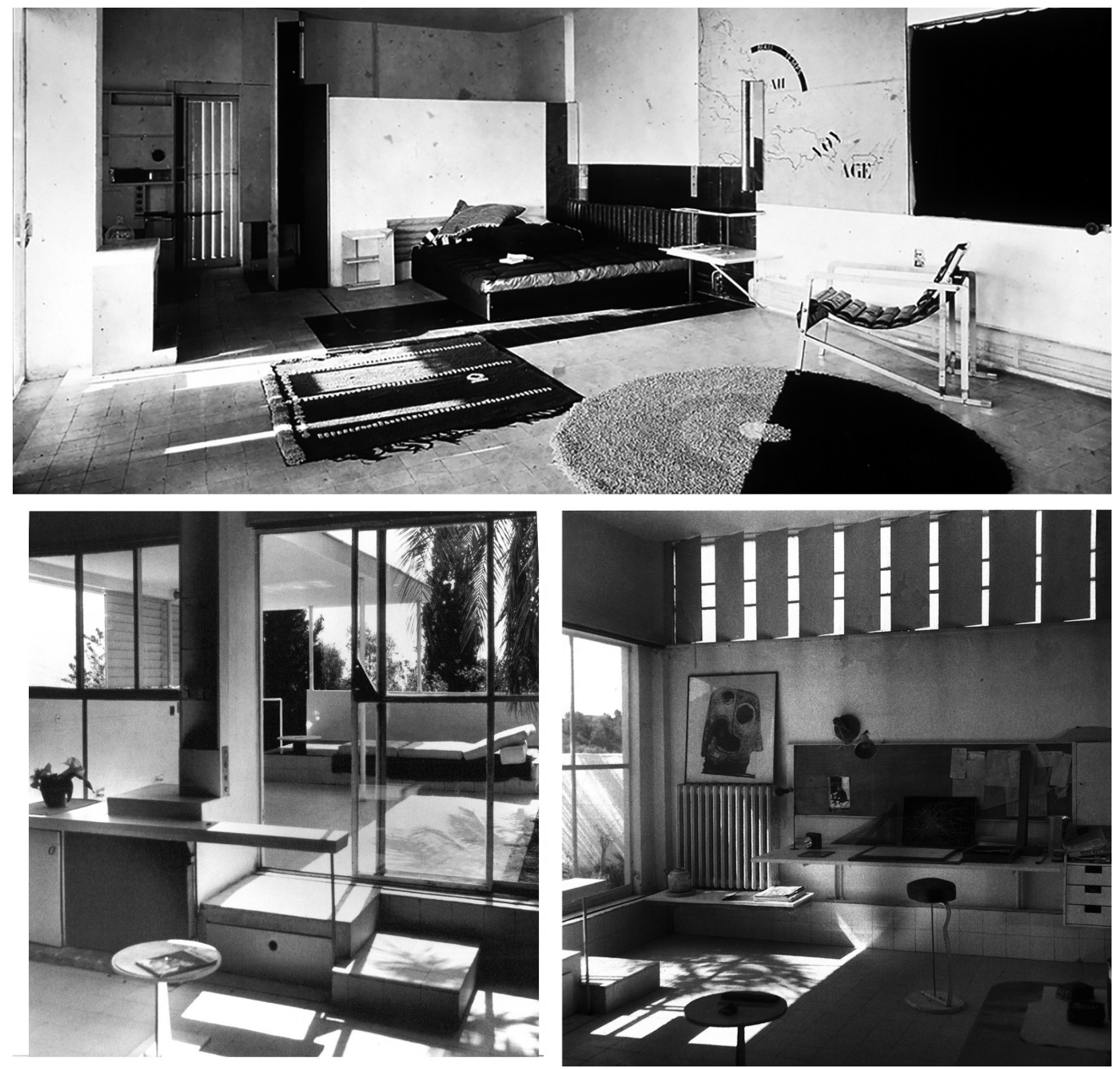

Figura 11. Estancia principal de E.1027. Maison en Bord de Mer (1926-1929) y estancia principal de Tempe à pailla (1932-1934)

Fuente: A: Adam, 2009, p. 197. B: Adam, 2009, 235. C: Adam, 2009, 237

La exploración material y lumínica revela una invitación a lo táctil, a la interacción íntima entre individuo y arquitectura inspirada en la vida cotidiana. Cada material tiene su sentido en función del uso al que se destina, y siempre es elegido para resolver un problema funcional, responder a una forma deseada o producir un significado preciso. Su conocimiento íntimo y el control de las posibilidades intrínsecas de los acabados y texturas proceden de su formación artesanal y de su experiencia como interiorista. El espíritu de sofisticada sencillez zen encarnada en su arquitectura podría explicarse a través de las enseñanzas de su maestro Sugawara, quien debía ser algo más que un mero artesano, como prueba el hecho de que al finalizar su colaboración con ella recibiera el encargo de atender la colección Rothschild en Cernay-la-Ville (Constant, 2000, p. 237).

El diseño del mobiliario de Gray refleja la búsqueda de una expresión artística indiscutible, de factura artesanal, e invitan a recordar su admiración por la obra de C.R Mackintosh, que había conocido en la Exposición Universal de París de 1900 (Polan, 2011). Tal vez esa artisticidad vinculada a la singularidad de sus diseños explique por qué su dragon chair haya logrado batir el récord de ser la pieza más cara de mobiliario jamás subastada hasta la fecha. Observando la delicadeza y la belleza de sus diseños, uno tiende a pensar que, más que de objetos diseñados, se trata de verdaderos objetos artísticos, concebidos no para ser reproducidos en serie con la repetitividad del oficio artesano a la que hace referencia Sennet (2009), sino, más bien, para ser ejecutados como obras únicas.

La producción de Gray en las obras analizadas -y de forma singular en las dos viviendas en el las que el despliegue de la compleja materialidad del proyecto cristaliza, E.1027 y Tempe à pailla-, muestra la verdadera crítica que su genio dirigía a la modernidad funcionalista y, en buena medida, al canon corbusierano; un entendimiento del habitar mucho más intimista, sensual y femenino que establece un sabio diálogo con el lugar, rechazando la noción de máquina de habitar que, como tal, podría estar situada en cualquier lugar. Es precisamente esa crítica expresada con palabras y cincelada en la combinación equipamiento y arquitectura la que debe prevalecer como la mejor aportación de Gray, materializada memorablemente en Cap Martin y en Castellar (Marcos y Swisher, 2021, p. 495). 
Anatomía arquitectónica en la obra de Eileen Gray. Un análisis comparado para identificar la mano tras el diseño de la E.1027

\section{Conclusión}

La identificación de la E.1027 con una moderna obra total puesta al servicio de la vida cotidiana, y su análisis comparado con el resto de proyectos analizados en este artículo -elaborados por Gray en solitario, tanto anteriores como posteriores- confirman la hipótesis inicial de su indiscutible protagonismo en la autoría de esta vivienda. Las referencias, los ensayos y la calidad de la obra analizada ilustran su logro de destilar las dos tendencias dominantes de la incipiente modernidad arquitectónica de la época: el neoplasticismo con el funcionalismo más habitable.

La crítica basada en prejuicios respeto al hecho de que Gray fuera mujer, y careciera de formación académica, no debe distorsionar el debate sobre la calidad indiscutible de su arquitectura, representada de manera sobresaliente en la E.1027. Las bondades y la eficacia de su diseño permiten colocar su producción al nivel de los maestros de la modernidad, incluso a pesar de la escasez de su obra construida. Para la crítica lo más importante es el logro alcanzado por lo concreto de lo producido, no su autor o cualquier circunstancia que adjetive su existencia.

En esta investigación se han analizado e identificado una serie de cualidades que caracterizan su elaborada manera de entender la arquitectura, así como su rico y sofisticado vocabulario formal. La compleja densidad espacial, su atención al diálogo entre lugar y arquitectura, añadidos al exquisito detalle de su mobiliario, son rasgos que, observados bajo la lente de la crítica arquitectónica, coinciden en estos proyectos y obras, evidenciando un mismo proceder; un modo con el que, sin embargo, no encontramos semejanzas ni equivalencias respecto a los ejemplos proyectados en solitario por Badovici en Vézelay, que muestran una fuerte impronta corbusierana, diferenciada de la línea más neoplasticista de Gray.

De dicho análisis parece lógico deducir que la mano sabia y delicada que alumbra el diseño de la E.1027. Maison en bord de mer corresponde con toda probabilidad a Gray lo que relega a Badovici a un papel de consultor técnico y acompañante sagaz de olfato crítico memorable; algo que resulta evidente tanto por la extraordinaria selección documental realizada en su labor de director de L'Architecture Vivante, como en la elección de Gray para el diseño de la E.1027 o la remodelación de su apartamento en el Rue de Chateaubriand de París. Con todo, una obra de arquitectura construida es más que su mero proyecto dibujado; por ello, resulta evidente que Badovici debió jugar, además, un papel determinante en los aspectos constructivos y estructurales de la vivienda.

El entendimiento de la E.1027 con su entorno próximo y la relación sensual del habitante con la su arquitectura supusieron una crítica coetánea al canon que consideraba la arquitectura moderna como objeto abstracto y virtualmente ubicuo. La materialidad artesana de todos sus objetos, derivada de su aprendizaje en las técnicas de lacado y del textil, junto a su estratégico dominio del espacio arquitectónico, demuestran un entendimiento casi zen y una prodigiosa capacidad de elaborar el detalle.
La concepción de arquitectura y equipamiento como manifestación artística unitaria, rasgo común de la obra de Gray, ha permitido identificar los rasgos fundamentales de su quehacer arquitectónico y demostrar su protagonismo en el proyecto de la E.1027, materializado en la sobria exquisitez de ese sueño construido.

\section{Agradecimientos}

Agradecemos las aportaciones, matizaciones y aclaraciones realizadas por investigadores reconocidos sobre la materia, como son Caroline Constant, Tim Benton y Carmen Espegel en el curso de esta investigación. A ellos acudimos cuando sobre algún tema en particular tuvimos dudas o las fuentes bibliográficas no permitían conocer con precisión. Todos amablemente respondieron a nuestras inquietudes contribuyendo a mejorar el texto, aunque ello no implique que estén de acuerdo con todas las opiniones y los juicios vertidos en el mismo.

Cómo citar este artículo/How to cite this article: Marcos-Alba, C L. y Moreno-Moreno, Ma. P. (2022). Anatomía arquitectónica en la obra de Eileen Gray. Un análisis comparado para identificar la mano tras el diseño de la E.1027. Estoa. Revista de la Facultad de Arquitectura y Urbanismo de la Universidad de Cuenca, 11(21), 155-168. https://doi.org/10.18537/ est.v011.n021.a13

\section{Referencias bibliográficas}

Adam, P. (2009). Eileen Gray. Her life and work. Ed. Thames \& Hudson.

Badovici, J. (1924). L'art d'Eileen Gray. Wendingen, (6), 12-16.

Badovici, J. (Otoño-Invierno 1926). L'Architecture Utilitaire. L'Architecture Vivante, 17-24

Barrès, R. (2000). E.1027: Vers une restaurationn active d'un manifeste de l'architecture moderne, Essai d'une théorie de restauration active du patrimoine modern et contemporain. (pp. 105-229). Editions d L’Espérou.

Benton, T. (2017). E.1027 and the Drôle de Guerre. AA Files, 74, 123-143.

Colomina, B. (2001). Líneas de Batalla: E. 1027. En Pa sajes. (pp. 47-55). Centro de Estudios Amancio Williams. Univ. de Buenos Aires.

Constant, C. (2000). Eileen Gray. Ed. Phaidon, Press Limited.

Constant, C. (1994). The Nonheroic Modernism of Eileen Gray. Journal of the Society of Architectural Historians, 53(3), 265-279. 
Constant, C. y Wang, W. (1995). Eileen Gray: an architecture for all senses. Deutsches Arkitektur Museum. Harvard University graduate school of design.

De Clermont-Tonnerre, E. (1922). The Laquer Work of Miss Eileen Gray. The living Arts, (3), 148.

Espegel Alonso, C. y Movilla Vega, D. (2011). E.1027. Maison en bord de mer: theoretical restoration. En M Domingo e I. Muiña (Eds.) Criterios de Intervención En el Patrimonio Arquitectónico del Siglo XX: Conferencia Internacional CAH20thC: Documento de Madrid 2011 (pp 301-310). Ministerio de Cultura.

Espegel Alonso, C. (1997). Proyecto E:1027 de Gray-Badovici, drama de la villa moderna en el Mediterráneo [Tesis doctoral, Universidad Politécnica de Madrid].

Espegel Alonso, C. (2010). Aires Modernos. E.1027: maison en bord de mer. Eileen Gray y Jean Badovic 1926 1929. Ed. Mairea Libros.

Espegel Alonso, C. (2011). Eileen Gray. Invitación al viaje Ed. Fundación Caja de Arquitectos.

Fernández-Cobián, E. (2013). Aires Modernos. E.1027: maison en bord de mer Eileen Gray y Jean Badovici, 1926-1929. Boletín Académico. Revista de investigación y arquitectura contemporánea BAC (3), 75-76.

Galiano-Garrigós, A., Marcos, C. L., Kouider, T. y Gutiérrez, P. J. (2021). Reassessing thermal comfort in modern architecture: E.1027 as a case study. Building Research \& Information, 49(6), 1-25.

Frampton K. (1987). Historia crítica de la arquitectura moderna. Gustavo Gili.

Frampton K. (1969). Maison de Verre. Perspecta (12) The Yale Architectural Journal. Traducido al español en (1988). Arquitectura. Revista del COAM (276), 26-43.

Gray, E. y Badovici, J. (Otoño-Invierno 1929). Du L'Éclectisme au Doute. L'Architecture Vivante, 17-21.

Gray, E. y Badovici, J. (Otoño-Invierno 1929). Description. L'Architecture Vivante, 23-38.

Gray, E. y Badovici, J. (1930). La maison minimum, pour le minimum de place, le máximum de confort cellules fixes \& cellules transformables. L'Architecture d'Aujourd'hui, 1(1)

Le Corbusier. (Otoño-Invierno 1933). Au revoir...à L'Architecture Vivante. L'Architecture Vivante, 33.

Le Corbusier. (1964). The Radiant City, Ed. Orion.

Marcos, C. L. (2011). Crítica de género. E. 1027: Eileen Gray vs. Le Corbusier en Cap Martin. Feminismo/s, 17 , 259-295.

Marcos, C. L., y Swisher, M. (2021). The E-1027, That Obscure Object of Design. En C. Bartolomei, A. Ippolito, S. H. Tanoue Vizioli (Eds.) Digital Modernism Heritage Lexicon (pp.475-497). Ed. Springer.
Marín de Terán, L. (1976). La visita de la vieja dama, Eileen Gray. Arquitecturas Bis, (16), 7-18.

Morales, J. (2005). La disolución de la estancia: Transformaciones domésticas 1930-1960. Ed. Rueda S.L.

Moreno Moreno, Ma P. (2012). Intuición y método en el aprendizaje del proyecto: Eileen Gray reinterpreta a Adolf Loos. Vivienda de tres plantas, un ejemplo de meta-arquitectura. Vivienda Colectiva: Investigación, Crítica y Obra (pp. 185-199). Ed. Tres Fronteras.

Moreno Moreno, Ma P. (2017). El mecanismo espacial del Faux Plafond: Eileen Gray. BAC Boletín Académico, (7), 95-114. https://doi.org/10.17979/ bac.2017.7.0.1850

Polan, J. (Spring 2011). Eileen Gray. From Shadow to Light. Modernism, 42-51.

Rault, J. (2005). Occupying E.1027. Reconsidering Le Corbusier's "Gift» to Eileen Gray. Space and Culture, 8 (2), 160-179.

Rayon, J-P. (1985). Eileen Gray: I'Etoile du Nord et l'Etoile du sud. En B. Reichlin, Y-A. Bois Liège, \& P. Mardaga (Eds). De Stijl et la Architecture en France (pp. 121-138). L'Institut français d'architecture.

Ryan, D. J. (2010). Sunshine and shade in the architecture of Eileen Gray. Architectural Science Review, 53(3), 340-347.

Rykwert, J. (Dic.1968). Un omaggio a Eileen Gray. Pionera del Design. Domus (469), 21-34

Rykwert, J. (1971). Eileen Gray: Two houses and an interior, 1926-1933. Perspecta The Yale Architectural Journal, (13-14), 67-73.

Rykwert, J. (Dic. 1972). Eileen Gray: pioneer of design. Architectural Review 152 (910), 357-361

Sennet, R. (2009). El Artesano. Ed. Anagrama.

Van Doesburg, T. (Otoño-Invierno 1925). L'Evolution de la Architecture Moderne en Hollande. L'Architecture Vivante, 19-20.

Van Doesburg, T. (1927). Data en Feiten. De Stijl, VII (79/84), pp.53-71.

Zevi, B. (1960). Poética de la arquitectura neoplástica. Ed. Víctor Lerú S.R.L. 